\title{
Nola aurre egin itsas garraioak eragindako klima-aldaketari? Estrategia berriak
}

\author{
(New strategies to face Climate Change due to maritime transport)
}

\author{
Nestor Goicoechea ${ }^{1}$, Harkaitz Eguiraun*1,2, Ibon Galarraga ${ }^{3}$, \\ Eneko Solaberrieta ${ }^{4}$, Luis Maria Abadie 3 \\ ${ }^{1}$ Department of Graphic Design \& Engineering Projects, \\ Faculty of Engineering in Bilbao, UPV/EHU \\ ${ }^{2}$ Research Centre for Experimental Marine Biology \& Biotechnology, UPV/EHU \\ ${ }^{3}$ Basque Center for Climate Change (BC3), UPV/EHU \\ ${ }^{4}$ Department of Graphic Design \& Engineering Projects, \\ Faculty of Engineering Gipuzkoa, UPV/EHU
}

\begin{abstract}
LABURPENA: Gaur egun, itsas garraioak munduko ondasunen \% 90 mugitzen du. Ekonomiaren hazkundea eta globalizazioa direla-eta, garraio mota hori goraka doa. Munduko garraioontzi flotaren kopurua haziz doan neurrian, fuel-olioaren kontsumoa ere hazten ari da. Fuel-olioaren kostua garraio-ontzi baten kostu operazionalen \% 50 baino gehiago da, eta erregai horren erabilerak eragin nabarmena du ingurumenean (azidifikazioa, kutsadura, berotegi-efektua...); hori kontuan izanik, ECA direlako guneetan (Emission Control Areas) banatu ditu munduko itsasoak IMOk (International Maritime Organization), ingurumen-legedi berezi baten pean. Artikulu honetan, aztergai da zer estrategia jarraitu behar duen armadore batek (itsasontzi baten ustiatzaileak) lege sorta horietara egokitzeko, honako hiru aldagai hauek kontutan izanda: i) eraikita dagoen itsasontzi bat ustiatzen badu, sufre gutxiagoko fuelak erabiltzea edo itsasontziaren motorra egokitzea; ii) itsasontzi berri bat eraikitzera badoa, motor duala edo diesel-motorra jartzea; eta iii) zer aukera dagoen IMOk ECA gune berriak sortzeko.
\end{abstract}

HITZ GAKOAK: Itsas garraioa, itsas fuel-olioa, NOx, SOx, ECA guneak, itsas motor duala, itsas motor diesela, scrubber.

ABSTRACT: Currently maritime transport is growing due to globalization and economic growth, and it transports approximately the $90 \%$ of the world's goods. World maritime transport fleet is increasing in amount and in size of vessels and, accordingly, marine fuel oil consumption is also increasing. The marine fuel oil consumption represents the 50\% of the operational costs of a vessel and it has a huge environmental impact (ocean acidification, pollution, greenhouse effect, climate change...). Consequently, IMO (International Maritime Organization) created a specific environmental regulation and divided the ocean in different ECA zones (Emission Control Areas). The present work analyses the best strategy, a shipowner should adopt, to comply with ECA regulations, in three different panoramas: $i)$ using an active vessel, placing a scrubber or consuming low sulphur marine fuel oil; ii) constructing a new vessel, choosing between marine dual engine or marine diesel engine in both cases with or without scrubber; and iii) in case new ECA zones are created, which affects directly the vessel's operational area.

KEYWORDS: Maritime transport, marine fuel, NOx, SOx, ECA zones, marine dual engine, marine diesel engine, scrubber.

* Harremanetan jartzeko / Corresponding author: Harkaitz Eguiraun, Department of Graphic Design \& Engineering Projects, Faculty of Engineering in Bilbao, UPV/EHU. Euskal Herriko Unibertsitatea (UPV/EHU), S Torres Quevedo Enparantza 1 48013 Bilbo, Bizkaia. Euskal Herria. - harkaitz.eguiraun@ehu.eus - https://orcid.org/0000-0002-4014-6376.

Nola aipatu / How to cite: Goicoechea, Nestor; Eguiraun, Harkaitz; Galarraga, Ibon; Solaberrieta, Eneko; Abadie, Luis Maria (2020). "Nola aurre egin itsas garraioak eragindako klima-aldaketari? Estrategia berriak»; Ekaia, ale berezia 2020, 79-94. (https://doi.org/10.1387/ekaia.21188).

Jasoa: 25 urria, 2019; Onartua: 03 abendua, 2019

ISSN 0214-9001 - eISSN 2444-3255 / (c) 2020 UPV/EHU

(i) (i) Obra hau Creative Commons Atribución 4.0 Internacional-en

lizentziapean dago 
Nestor Goicoechea, Harkaitz Eguiraun, Ibon Galarraga, Eneko Solaberrieta, Luis Maria Abadie

\section{ITSAS GARRAIOA GAUR EGUN}

Gaur egun, itsas garraioak munduko ondasunen \% 90 mugitzen du [1]. Ekonomiaren hazkundearekin eta globalizazioarekin, 1970eko hamarkadatik etengabe haziz joan den sektorea izan da, bai ondasunen kopuruaren aldetik (1. irudia), bai flotaren tamainaren aldetik (2. irudia) [2]. Bitxikeria modura, aipatzekoa da 2009. urtean munduko krisi ekonomikoak eragindako hazkunde negatiboa.

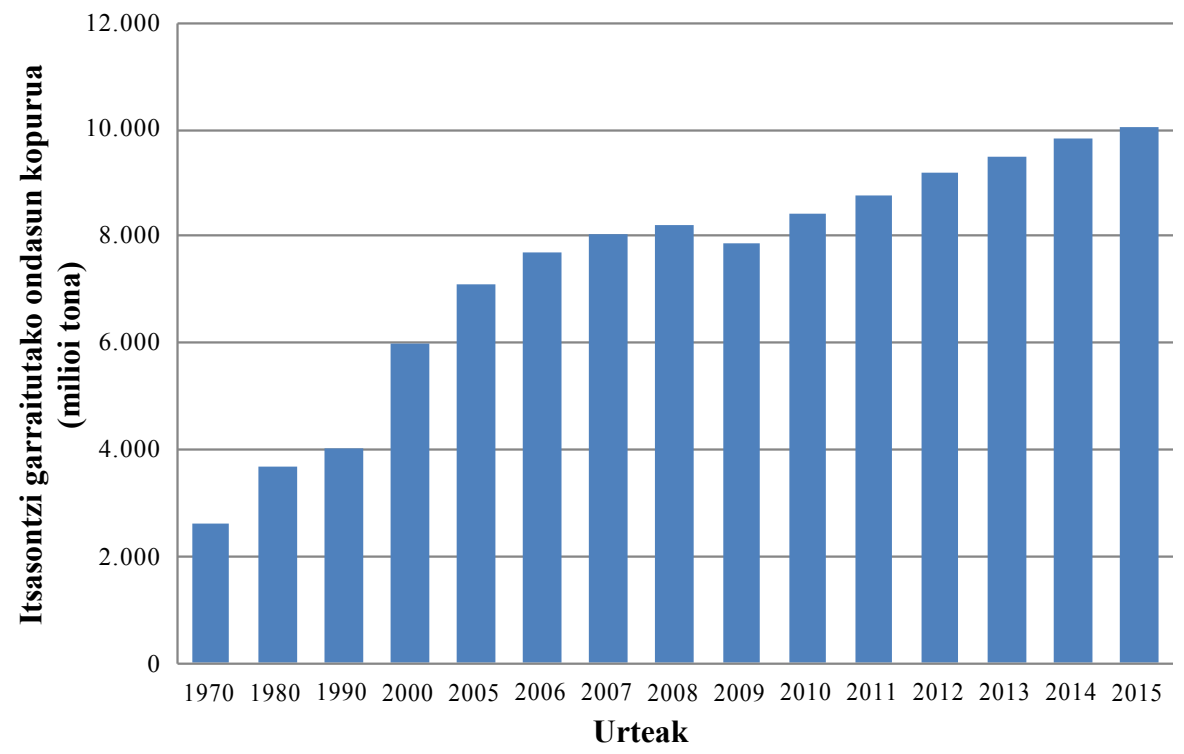

1. irudia. Munduko itsas garraioaren bilakaera: 1970-2015 urteen bitartean, 2.600 milioi tona inguru garraiatzetik 10.000 milioi tona garraiatzera heldu da. Egileek prestatua, UNCTADeko [2] datuekin, eta [4]-n publikatua.

Etorkizunera begira kopuru bateraturik ez dagoen arren, joera argia da. International Chamber of Shipping-en arabera [1], 17.000 milioi tona ondasun mugituko dira 2030.ean itsas garraio bidez; Global Marine Trends-entzat, berriz, kopuru hori 20.000 milioi tonakoa izango da [3].

Garraiatutako ondasun kopuruaren eta itsasontzi kopuruaren hazkundeek ondorio zuzen-zuzena dute: fuel-olioaren eskariaren hazkundea. Horrekin lotuta, beste zenbait faktore hartu behar dira kontuan, hala nola erregai horren prezioa, erabilgarritasuna eta zer-nolako inpaktua duen hala planetan nola gizakiongan. 


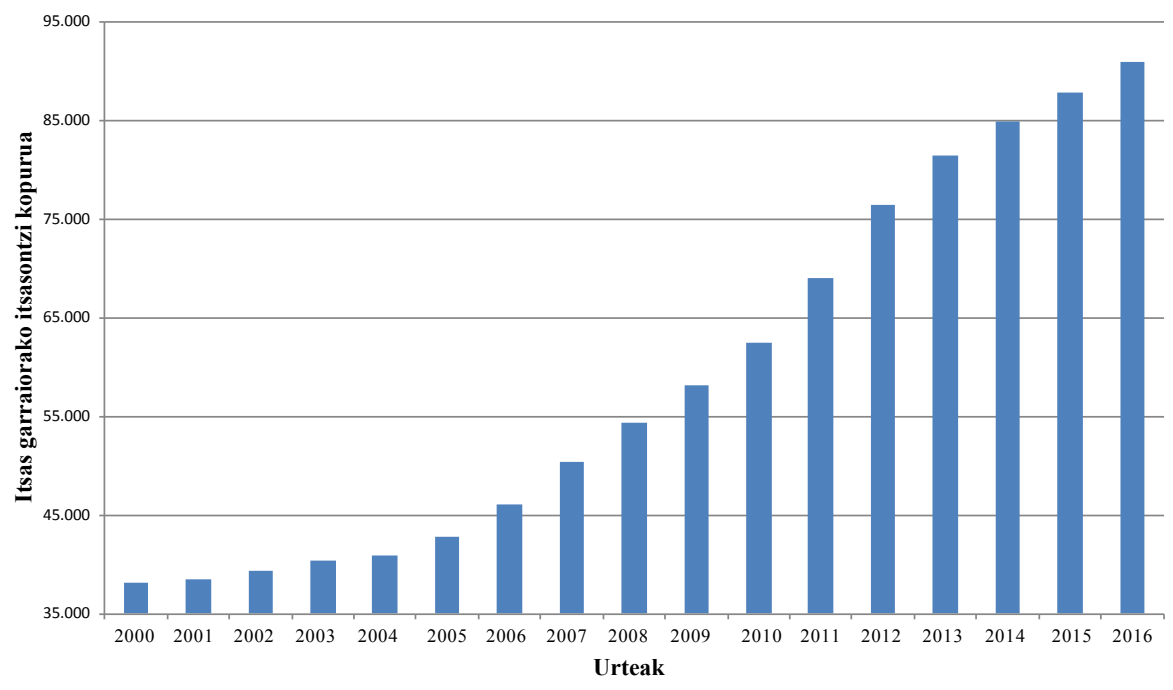

2. irudia. Munduko itsasontzi-flotaren hazkundea 2000-2016 urteen bitartean. Hamasei urtean, hirukoiztu egin da merkataritza-garraiorako itsasontzien kopurua munduan. Egileek prestatua, UNCTADeko datuekin [2].

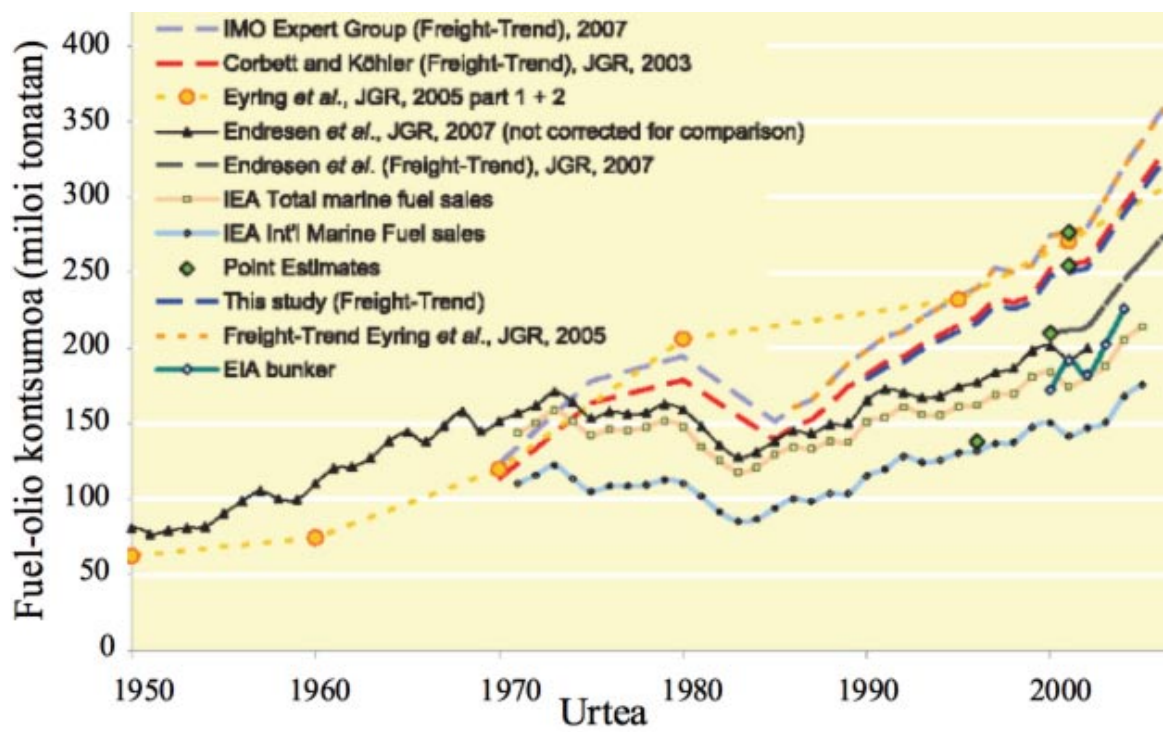

3. irudia. Munduko itsasontzi-flotak kontsumitutako fuel-olio kopurua (milioi tonatan), 1950-2010 urteen bitartean [11], zenbait ikerkelariren kalkuluen arabera. Aipatzekoa da lan ezberdinek jarraitutako metodologia-datuen konbinazioari esker emaitza ezberdinak agertzen direla, baina joera goranzkoa dela beti. Puntuak, grafikoan, kalkulatutako balioak dira, eta lerroak, puntuen harteko iragarpenak. 
Nestor Goicoechea, Harkaitz Eguiraun, Ibon Galarraga, Eneko Solaberrieta, Luis Maria Abadie

Fuel-olioaren kontsumoa oso faktore garrantzitsua da itsas garraioan. Izan ere, kostu operatiboen (OPEX Operational Expenses) \% 50 baino gehiago izan daiteke [5, 6, 7], eta lotura zuzena du berotegi-efektuko gasekin (GHG Green House Gas): fuel-olioaren kontsumoa handitzen den neurrian, berotegi-efektuko gasen kopurua ere handitzen da. Fuel-olioaren kontsumoaren neurketa, izatez, erronka handia da; hainbat ikerlarik jardun dute, metodo ezberdinez, neurketak egiten, eta emaitza ezberdinak izan dituzte. Errealitate hori 3. irudian ikusten da [8, 9, 10, 11]. Halako lanak bi multzotan sailka daitezke: 1) jarduera jakin bateko datuetan oinarritutakoak, eta 2) fuel-olioaren kontsumoen estatistiketan oinarriturikoak. Lan horien emaitzak aztertuta bi ondorio atera daitezke: batetik, ziurgabetasun handia dagoela eta, bestetik, fuel-olioaren kontsumoaren joera hazkorra dela.

Adibidez, 4. irudian, jardueren datuetan oinarritutako analisia adierazten da, eta IMOren bi ikerketatan oinarrituta dago [11,12]. Bertan, urteak aurrera joan ahala fuel-olio kontsumoa haziz doa. Estatistiketan oinarritutako analisian, aldiz, nahiz eta goranzko joera mantendu, kontsumo-datuen balioak txikiagoak dira, erabilitako estatistikek ez baitute kontuan hartzen itsasontzi batek kontsumitzen duen fuel-olioa ez dela nahitaez erosi behar itsasontziak hornitzeko leku berezietan.

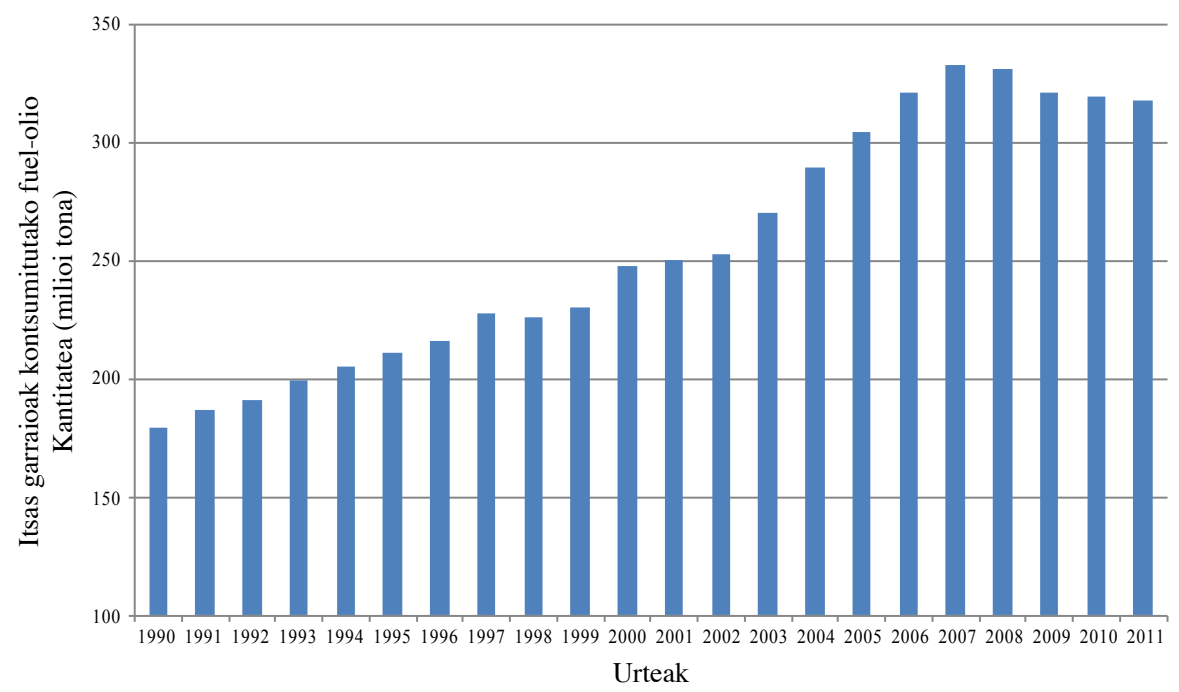

4. irudia. Munduko itsasontzi-flotak kontsumitutako fuel-olio kopurua (milioi tonatan), 1990-2011 urteen bitartean, IMOko bi ikerketatan oinarrituta [11, 12]. Kontsumoaren joera goranzkoa da, 2008-2009ko mundu krisi ekonomikora arte. Egileek prestatua. 


\section{ITSAS FUEL-OLIOA: PLANETAN ETA GURE OSASUNEAN DUEN INPAKTUA}

Itsas garraioaren fuel-olioaren kontsumoak harreman zuzena du gai kutsatzaileak airera isurtzearekin [10]. Adibidez, 2007an, itsas garraioko flotan izan zuten oinarria munduko $\mathrm{CO}_{2}$ isurketen $\% 4 \mathrm{k}$ eta berotegiefektuko gasen isurketen \% 2,8k [1, 13]. IMOk 2014an adierazitakoaren arabera [12], itsas garraioak, urtero, 1.000 tona inguru $\mathrm{CO}_{2}$ isurtzen ditu atmosferara, eta garraio horretan dute jatorria berotegi-efektuko gasen isurketen $\% 2,5 \mathrm{ek}$. Hala eta guztiz ere, itsas garraioak, beste garraio mota batzuen aldean, ondasunen garraiorako biderik efizienteena izaten jarraitzen du. Ikus bedi, adibidez, 1. taula, non adierazten den zenbat $\mathrm{CO}_{2}$ gramo isurtzen den itsas garraioan atmosferara garraiatutako ondasun tona metriko bakoitzeko eta kilometro bakoitzeko (trenbideko, aireko eta kamioi bidezko garraioarekin alderaturik ageri da).

1 taula. Zenbat $\mathrm{CO}_{2}$ gramo isurtzen den garraiatutako ondasun tona metriko bakoitzeko eta kilometro bakoitzeko, garraio motaren arabera. Egileek prestatua, iturri hauetatik [14], eta jada publikatua [15].

\begin{tabular}{lc}
\hline \multicolumn{1}{c}{ Garraio mota } & $\mathrm{CO}_{2}$ isurketa \\
\hline Hegazkina & $450-500 \mathrm{~g}$ \\
Kamioia & $60-150 \mathrm{~g}$ \\
Trena & $30-100 \mathrm{~g}$ \\
Itsasontzia & $10-40 \mathrm{~g}$ \\
\hline
\end{tabular}

$\mathrm{CO}_{2}$ ez ezik, beste sustantzia oso kutsakor batzuk ere isurtzen dituzte fuel-olioa erretzen duten itsasontziek, hala nola nitrogeno-oxidoak (NOx), sufre-oxidoak (SOx), metal astunak, hidrokarburo aromatiko poliziklikoak edota konposatu organiko lurrunkorrak $\left(\mathrm{PM}_{2.5}\right)$. Kutsatzaile horiek, klima-aldaketan ez ezik [10], eragina dute, halaber, gure osasunean eta itsasoen azidotzean [16, 17]. Gizakion ikuspuntutik, itsas garraioko fuel-olioak eragindako airearen kutsadurak osasun-arazo larriak ekar ditzake, hala nola bihotz-arnas aparatuko arazoak (400.000 heriotza goiztiar gutxi gorabehera urtean), umeen asma (14 milioi kasu inguru urtean), biriketako minbizia eta, azkenik, heriotza [18]. Fuel-olio garbiagoak erabiltzeak berekin ekarriko luke atmosferaren kutsaduratik eratorritako heriotzak \% 2,6 eta umeen asma \% 3 murriztea. Hala ere, ez dugu ahaztu behar itsas merkataritza ibilbideen ondoko kostetan dauden populazio handiko eskualdeek, gehienbat, halako eraginak jasaten jarraituko dutela [19]. 
Nestor Goicoechea, Harkaitz Eguiraun, Ibon Galarraga, Eneko Solaberrieta, Luis Maria Abadie

Etorkizunera begira, Sofiev-ek aztertzen du [19] zer-nolako inpaktua izango lukeen 2020. urterako fuel-olio garbiagoak erabiltzeak (sufre gutxiagokoak). Azterlan horren arabera, itsas fuel-olioa erretzetik sortutako $\mathrm{PM}_{2.5}$-ak murriztuta, heriotza-tasa eta erikortasuna gutxitu egingo lirateke: $\% 34$ eta \% 54, hurrenez hurren. Gainera, fuel-olio garbiagoak erabiliz, $\% 80$ murrizten da itsasontzien aerosolen hozte erradiaktiboa.

\section{NAZIOARTEKO LEGEDIAK ETA ECA EREMUAK}

Orain arte azaldutakoari aurre egiteko, nazioarteko zenbait legedi egin izan dira azken urteotan. IMO itsasoko gaietarako Nazio Batuen agentzia espezializatua da, eta, besteak beste, honako bi erantzukizun nagusi ditu: i) itsasontzien eta itsastarren segurtasuna eta ii) itsasontzien jarduerek sortutako kutsaduraren prebentzioa. Azken horretarako, MARPOL hitzarmena (International Convention for the Prevention of Pollution from Ships) sortu zuen 1973. urtean. Urteetan zehar zenbait aldaketa egin zaizkion arren, gaur egun indarrean jarraitzen du. 2011. urtean, eta MARPOLen barruan, Energy Efficiency Design Index (EEDI) eta Ship Energy Efficiency Management Plan (SEEMP) deiturikoak garatu ziren. Oro har, itsasontzien errendimendua handitzeko eta sortzen duten kutsadura murrizteko ekintzak dira, eta ordutik aurrera eraikitako itsasontzi guztiek bete behar dituzte, unean uneko teknologiarik onena erabiliz (Best Available Technologies BAT).

2016ko urrian, IMOk SOx eta NOx araudi berriak ezarri, eta ECA direlako guneak sortu zituen (Emission Control Area). ECA guneon helburua, oro har, itsasontzien jarduerak osasunean eta ingurumenean dituen eragin kaltegarriak/txarrak murriztea da, eta munduko zenbait itsasotara mugaturik dago (5. irudia). Gaur egungo ECA guneak lehenagoko SECA (Sulphur Emission Control Areas) guneetan oinarrituta daude, eta honako gune eta arau hauetara mugatuta:

- Itsaso Baltikoa: SOx (1997. urtean adostua, derrigorrezkoa 2005etik) eta NOx (adostua 2016an eta derrigorrezkoa 2021ean).

- Ipar Itsasoa: SOx (derrigorrezkoa 2005ean) eta NOx (adostua 2016an eta derrigorrezkoa 2021ean).

- Ipar Amerikako mendebaldeko kostaldea (AEB eta Kanadako kostaldeak): NOx eta SOx (adostua 2010ean eta derrigorrezkoa 2012an.

- AEBren Karibeko kostaldea, Puerto Rico eta Birjina uharte estatubatuarrak barne: NOx eta SOx (adostua 2011n eta derrigorrezkoa 2014an.

- Bestelako ECA guneen sorrera eztabaidan dago, adibidez, Australia, Japonia, Singapur, Mexiko edo Mediterraneo itsasoa [20]. Konkretuki, zenbait lanek aztertzen dute ea zer gertatuko litzatekeen Mediterraneoa ECA gune bihurtuz gero [21, 22]. 
Badira beste legedi batzuk ere, baina tokian tokiko eremuak erregulatzen dituzte; esaterako, Kostaldeko Uren Erregulaziorako Txinatar Legea, 2005eko abendukoa (Perla eta Yangzi ibaietako deltetan eta Bohai itsasoan dabiltzan itsasontziak derrigortuta daude $0,5 \mathrm{sufre} \mathrm{m} / \mathrm{m}$ baino gutxiagoko fuel-olioa erabiltzera) eta Europar Batasunaren 2005 urteko EU 2005/33/ EC direktiba (Europatik joan-etorrian dabiltzan ferryek, ECA gunean, $1,5 \mathrm{~m} / \mathrm{m}$ sufre-mugara heltzeko baimena dute, eta, edozein itsasontzi amarralekuan bi ordu baino gehiago egonez gero, fuel-olioaren sufre kantitatea ezin da $\% 0,1 \mathrm{~m} / \mathrm{m}$-tik pasatu).

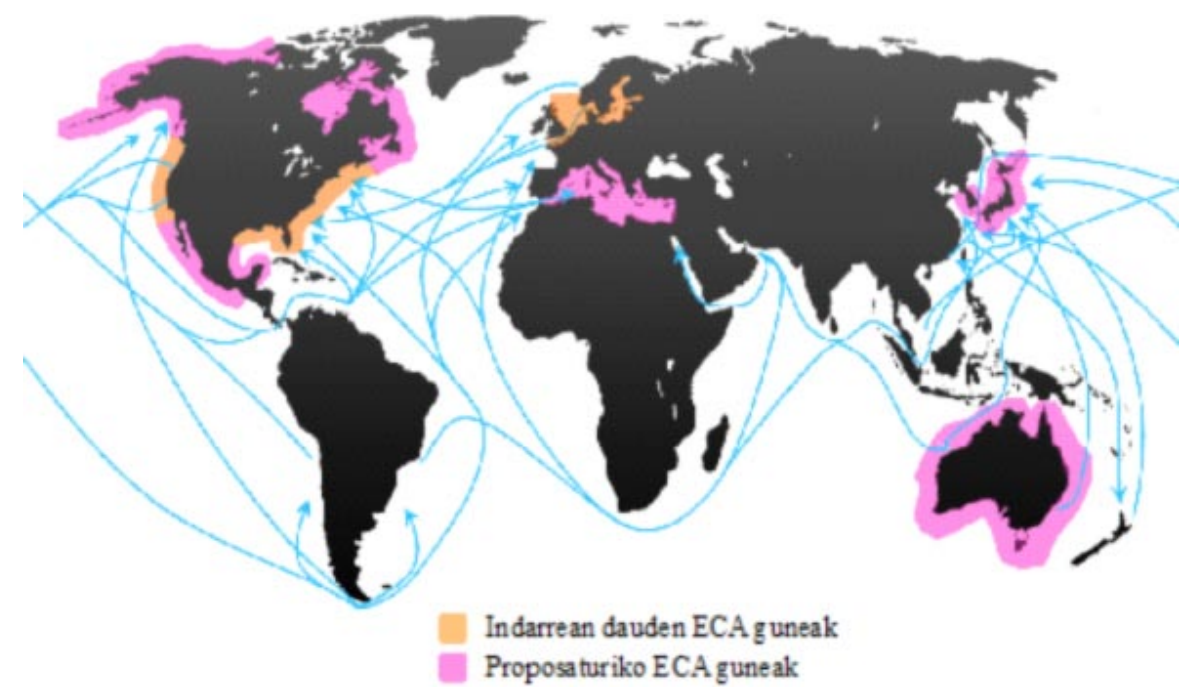

5. irudia. ECA guneen banaketa munduan zehar. Laranja-kolorez ageri dira indarrean dauden ECA guneak, eta arrosa-kolorez, berriz, proposaturiko ECA guneak. Itsas merkataritza bide nagusiak gezi urdinez adierazita agertzen dira [23].

\section{FUEL-OLIO MOTAK ETA MOTORREN ABIADURA}

Itsasontzien isurpenek harreman zuzena dute bi faktorerekin: erabiltzen duten fuel-olio mota eta motorraren erregimena. Nahiz eta asko kutsatzen duen erregai bat erabili, motorraren erregimena baxua baldin bada, itsasontzia ECA gune jakin batetik igarotzea gerta liteke.

Itsas merkataritzan erabiltzen diren fuel-olioak sailkatzeko orduan irizpide ezberdinak dauden arren, 2. taulan laburbildu dira gaur egun erabiltzen diren itsas garraiorako fuel-olio nagusiak. Zenbat eta sufre gehiago izan, orduan eta gehiago kutsatuko dute, printzipioz: 
Nestor Goicoechea, Harkaitz Eguiraun, Ibon Galarraga, Eneko Solaberrieta, Luis Maria Abadie

2 taula. Gaur egun itsas garraiorako erabiltzen diren fuel-olioen sailkapena sufre edukiaren arabera. Egileek prestatua Marquard \& Balhs-eko datuekin [24].

\begin{tabular}{|c|c|c|c|c|}
\hline Laburdura & Izena & $\begin{array}{c}\text { Sufre } \\
\text { kantitatea }\end{array}$ & $\begin{array}{c}\text { Biskositatea/ } \\
\text { dentsitatea } \\
\text { cSt (centistokes) }\end{array}$ & Oharrak \\
\hline $\begin{array}{l}\text { HFO edo } \\
\text { MFO }\end{array}$ & $\begin{array}{l}\text { Heavy Fuel } \\
\text { Oil edo Marine } \\
\text { Fuel Oil }\end{array}$ & $>\% 5$ & Oso altua & $\begin{array}{l}\text { Txapapote/galipot/mazut ere } \\
\text { deiturikoa. Mugitu ahal iza- } \\
\text { teko berotu behar da. }\end{array}$ \\
\hline IFO & $\begin{array}{l}\text { Intermediate } \\
\text { Fuel Oil }\end{array}$ & $\% 2-\% 5$ & 380 edo 180 & $\begin{array}{l}380 \text { koa } 180 \text { koa baino ga- } \\
\text { restiagoa da. Munduko itsa- } \\
\text { sontzien } \% 2,7 \mathrm{k} \text { gutxi gora- } \\
\text { behera mota hau erretzen du. }\end{array}$ \\
\hline $\mathrm{LS}$ & $\begin{array}{l}\text { Low Sulfur } \\
\text { Intermediate } \\
\text { Fuel Oil }\end{array}$ & $<\% 1$ & 380 edo 180 & $\begin{array}{l}\text { Findegietan sufrea kentzeko } \\
\text { instalazio espezifikoak behar } \\
\text { dira eta produktuaren prezioa } \\
\text { igotzen du. }\end{array}$ \\
\hline MDO & $\begin{array}{l}\text { Marine Diesel } \\
\text { Oil }\end{array}$ & $\% 2$ & 12 & $\begin{array}{l}\text { HFO eta bestelako mote- } \\
\text { tako fuelen nahasketa da. } \\
\text { HFOarekin konparatuz, bis- } \\
\text { kositate txikiagoa duenez ez } \\
\text { da berotu behar mugitu ahal } \\
\text { izateko. }\end{array}$ \\
\hline MGO & Marine Gas Oil & $\% 1,5$ & $<12$ & Destilatutako fuela da. \\
\hline LSMGO & $\begin{array}{l}\text { Low Sulfur } \\
\text { Marine Gas Oil }\end{array}$ & $<\% 0,1$ & $<12$ & $\begin{array}{l}\text { Kotxeen gasolina bezalakoa } \\
\text { da. }\end{array}$ \\
\hline ULSMGO & $\begin{array}{l}\text { Ultra Low } \\
\text { Sulfur Marine } \\
\text { Gas Oil }\end{array}$ & $<\% 0,0015$ & $<12$ & $\begin{array}{l}\text { Kotxeen gasolina bezalakoa } \\
\text { da. }\end{array}$ \\
\hline
\end{tabular}

Esan bezala, erabiltzen den fuel-olioa ez ezik, itsasontziaren motorraren erregimena ere izan behar da kontuan: zenbat eta erregimen altuagoan lan egin (motorrari gehiago eskatu), orduan eta kontsumo handiagoak egongo dira, eta, beraz, gero eta gehiago kutsatuko da. Hori saihesteko, ECA guneek, erabili daitekeen fuel-olioa ez ezik, fuel-olio hori nolako motor-erregimenarekin erabil daitekeen finkatzen dute, Tier mugapenekin. 6. irudian ikus daiteke, zer lotura duten motor-erregimenen abiadurak eta isurtzen diren NOx kopuruek. Tier III da araudirik modernoena eta murriztaileena (2016. urtekoa). Araudi hori betetzeko, itsasontzi berriak ezaugarri jakin batzuekin eraiki behar dira, eta itsasontzi zaharrak, nolabait egokitu. Adibidez, ECA gunean eta Tier III-an, $2.000 \mathrm{rpm}$ motor-erregimenarekin, isurpena ezin daiteke $2 \mathrm{~g} / \mathrm{kWh}$ ]. 


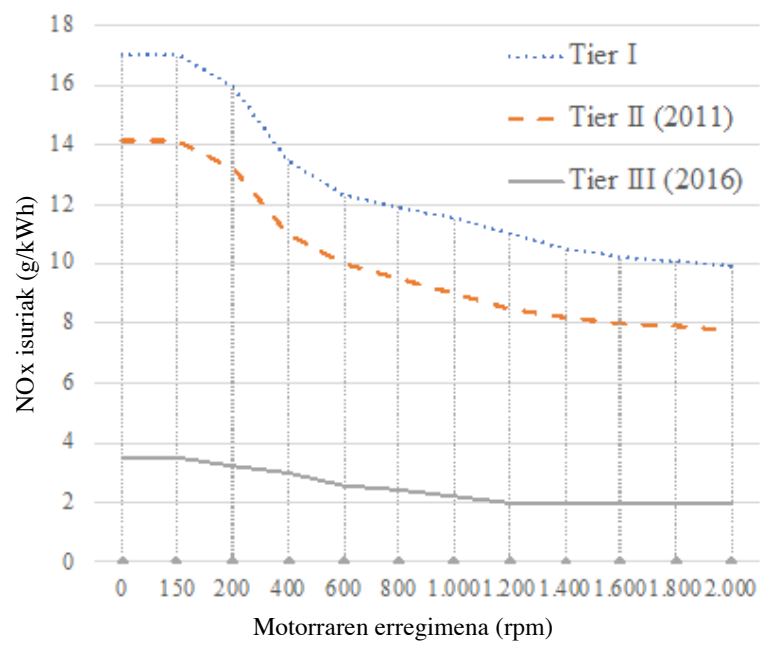

6. irudia. Nitrogeno-oxidoen erregulazioa motorraren erregimenaren eta Tier araudiaren arabera. Grafikoa [25]-etik egokituta.

SOx-ari dagokionez, 7. irudian adierazten da nola joan den murrizten isurketen erregulazioa urteen eta munduko tokien arabera. Besteak beste, agerikoa da 2010 eta 2015 urteetan ECA guneetan isurketei dagokienez gertaturiko aldaketa; hain zuzen ere, Tier II eta Tier III indarrean jarri zirenean.

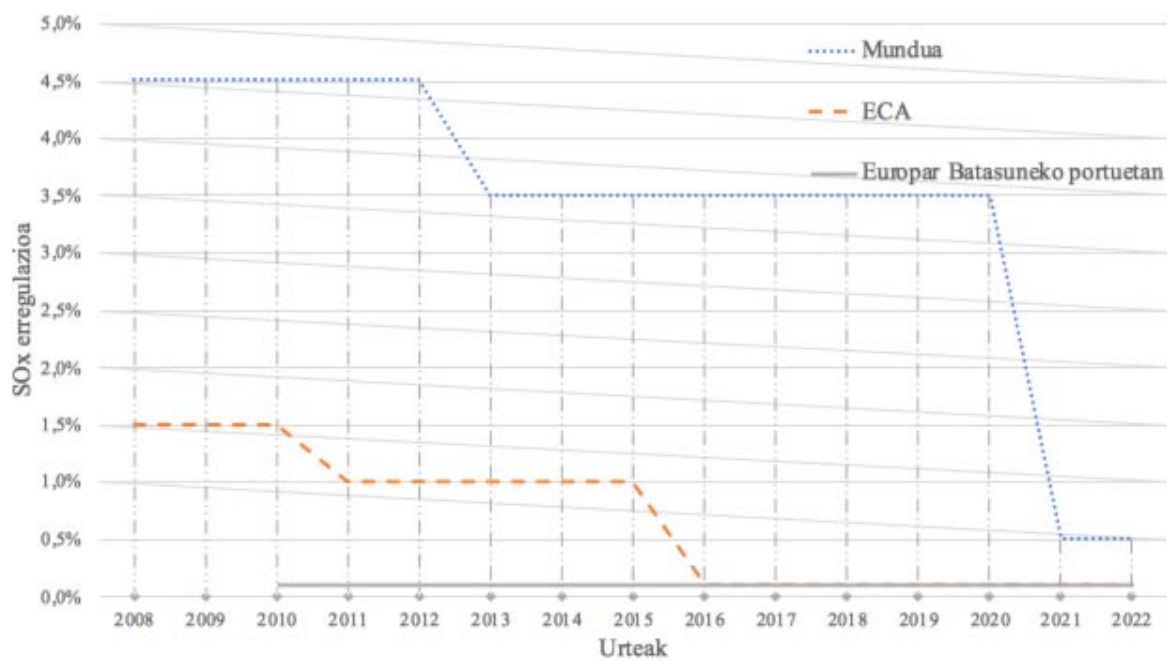

7. irudia. Sufre-oxidoen erregulazioa (2008-2022), guneen arabera: mundua, ECA guneak eta Europar Batasuneko portuak. Irudia [26]-tik egokitua. 
Nestor Goicoechea, Harkaitz Eguiraun, Ibon Galarraga, Eneko Solaberrieta, Luis Maria Abadie

\section{ARMADORE BATEK JARRAITU BEHARREKOAK}

Oro har, merkataritza-itsasontzi baten balio-bizitza 30 urte dela jotzen da; hala ere, armadoreek, askotan, luzatu egiten dute ontzien erabilera aldia. Armadore batek, 30 urte horiei begira, eta beraren inbertsioa errentagarri bihurtzeko eta etekina ahalik eta azkarren lortzeko, honako aldagai hauek aztertu behar ditu:

- Zer ECA eremutan jardungo duen itsasontziak.

- Propultsio-sistema, isurien gaineko araudiak betetzeko eta kontsumo txikia izateko.

- Zenbat egun igaroko dituen itsasontziak itsasoan.

- Erregai motaren prezio-aldaketak.

- Itsasontziari gelditzen zaion balio-bizitza.

- Itsasontzia bere balio-bizitzaren barruan egonda, legedi berri bat indarrean jartzea. Adibidez: ECA gune berriak sortzea, eta, beraz, itsasontzia bertatik igaroarazteko nolabait berriztatu behar izatea.

Aldagaiok kontuan izanda, armadorearen estrategia bi alderditan banatu daiteke:

1. Zer egin balio-bizitzaren barruan dagoen itsasontzi bat baldin badu.

2. Zer egin itsasontzi berri bat eraikiko badu.

\subsection{Eraikita eta balio-bizitzaren barruan dagoen itsasontzi baten kasua}

Historikoki, euren balio-bizitzaren barruan dauden itsasontziak, HFO erregaia kontsumitzeko diseinatu ziren. Petrolio-findegi batean, HFO azkenetarikoa agertzen da petrolioaren destilatze-zutabean, eta, horregatik, petrolioen eratorriz sorturiko erregaietatik merkeena da. Hala eta guztiz ere, halako itsasontzien motorrek, orokorrean, LSMGO delakoa ere erre dezakete, zeinak sufre kantitate askoz txikiagoa baitauka (2. taula), baina garestiagoa baita.

Horrenbestez, itsasontziak, ECA gunetik kanpo egotekotan, HFO erreko du, baina, ECA gune batera sartzean, bi gauza egin ditzake:

- LSMGO erretzea.

- HFOa erretzen jarraitzea eta bere motorra egokitzea, isuriak murrizteko scrubber delako sistema instalatuz.

Orokorrean, scrubber-a garbigune bat da, non gas-isurien sufrearen batezbestekoa murrizten den, baimendutako mailetaraino. Ikerketa batzuen 
arabera, scrubber-a instalatuta eta HFO erabiliz, SOx isurien \% 98 murriztea lortzen da $[27,28]$. Scruber sistema gasak «garbitzeko» hiru sistema motatan oinarrituta dago: i) zirkuitu zabalekoa, non itsas ura baino ez den erabiltzen, ii) zirkuitu itxia, non ur geza eta sosa kaustikozko nahasketa bat erabiltzen den, eta iii) sistema hibridoa, aurreko bien nahasketa bat (8. irudia).

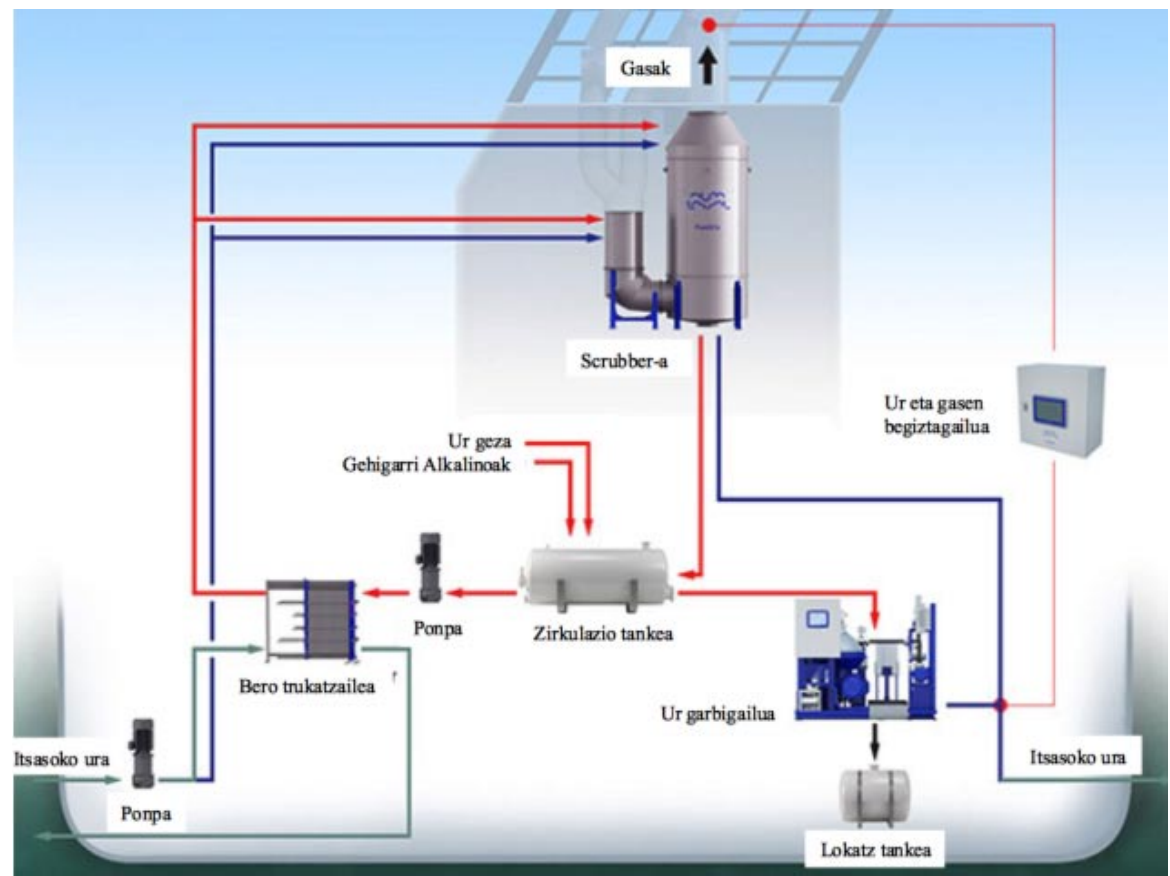

8. irudia. Scrubber sistema hibrido baten eskema.

Panasiuk-ek eta Turkina-k [28] aztertua dute zein den scrubber instalazio mota bakoitzaren kostua. Azterlan horren arabera, nahiz eta zirkuitu zabalekoa merkeagoa eta txikiagoa izan, beste aldagai batzuk hartu behar dira kontuan, hala nola motorraren ahalmena, itsasontziaren tamaina, kostu operatiboak (zenbat denbora itsasoan, portuan edo zain) eta mantentze-kostuak. Gure beste lanetik [15], ondorioztatu dugu ezinbestekoa dela, aurreko aldagaiez gainera, honako hauek ere aintzat hartzea: erregai mota aldatzeko aukera, zer ECA gunetan nabigatuko duen ontziak, zer ECA gune berri sor litezkeen eta itsasontziari gelditzen zaion balio-bizitza. Horrenbestez, scruberra instalatzea da aukera ekonomikorik egokiena (nahiz eta erregai kontsumoa eta $\mathrm{CO}_{2}$ isurpena handitu). Areago, zenbat eta gehiago nabigatu ECA guneetan, zenbat eta denbora gehiago igaro 
Nestor Goicoechea, Harkaitz Eguiraun, Ibon Galarraga, Eneko Solaberrieta, Luis Maria Abadie

itsasoan eta zenbat eta luzeagoa izan ontziaren balio-bizitza, orduan eta aukera egokiagoa da [15].

\subsection{Itsasontzi berri bat eraikitzearen kasua}

Merkataritza-itsasontzi berri batean, 3 motor mota jar daitezke: i) diesel-motorra, ii) motor elektrikoa eta iii) motor duala. Azken horretan, hiru erregai mota erabil daitezke: LSMGO, HFO edo LNG (Liquefied Natural Gas). Teknologian gertatu den bilakaera ikusita, motor duala, gaur egun, teknologikoki heldutzat jo daiteke. Oso gutxi kutsatzen du, eta diesel-motorrarekin konparatu izan dugu, itsasontzi berri bat eraikitzerako orduan [4]. 3. taulan laburbiltzen da propultsio-sistema bien arteko ezberdintasuna, kontsumitzen duten erregaiari begira eta ECA gunearen barnea edo kanpoan nabigatzen den kontuan izanda:

3 taula. Diesel-motorra edo motor hibridoa erabiliz kontsumitu behar den erregaia, ECA guneetan edo haietatik kanpo [4].

\begin{tabular}{clll}
\hline & & \multicolumn{1}{c}{ ECA gunean } & \multicolumn{1}{c}{ ECA gunetik kanpo } \\
\hline \multirow{2}{*}{ Diesel } & Scrubber & HFO & HFO \\
& Ez scrubber & LSMGO & HFO \\
\hline \multirow{2}{*}{ Dual (Diesel + LNG) $)$} & Scrubber & HFO edo LNG & HFO edo LNG \\
& Ez scrubber & LSMGO edo LNG & HFO edo LNG \\
\hline
\end{tabular}

Konkretuki, 5 MW Wärtsila diesel-motor baten eta haren dualaren arteko aldea aztertzen da, honako itsasaldi honetan: Port Said-etik (Egipto) Algeciras-era (Espainia) eta handik Bergen-era (Norvegia). Katalogoei begira, motor bien kontsumoa berdina den arren, Mediterraneo itsasoa ez da ECA gunea eta europar iparraldea bai. Etorkizunean, oso litekeena da Mediterraneoa ECA gune bihurtzea. Horregatik 4. taulan konparatzen da ea zein izango litzatekeen motorrik egokiena Mediterraneoa 2025ean eta Europa guztiko kostak 2030ean ECA gune bihurtuz gero. Motor duala diesela baino askoz moldagarriagoa da, LNG zein bestelako fuel-olioak kontsumi ditzakeelako, nahiz eta hasierako inbertsioa handiagoa izan. Taularen analisian, kontuan izan da zer gorabehera gerta litezkeen erregaien prezioetan itsasontziaren balio-bizitza osoan zehar. Azkenik, agerian gelditzen da zein den aukerarik zentzuzkoena: motor duala scrubberarekin. 
4 taula. $5 \mathrm{MW}$ Wärtsila diesel-motor baten eta haren dualaren artean teknologiarik egokiena zein den, kontuan harturik 2025ean Mediterraneoa ECA gune bihurtzeko probabilitatea eta 2030ean Atlantikoa ECA gune bihurtzekoa [4].

\begin{tabular}{|c|c|c|c|c|c|c|}
\hline \multirow{2}{*}{\multicolumn{2}{|c|}{$\begin{array}{c}\text { Teknologiarik } \\
\text { merkeena }\end{array}$}} & \multicolumn{5}{|c|}{ 2025ean Mediterraneoa ECA gune bihurtzeko probabilitatea } \\
\hline & & $\% 0$ & $\% 25$ & $\% 50$ & $\% 75$ & $\% 100$ \\
\hline \multirow{5}{*}{ 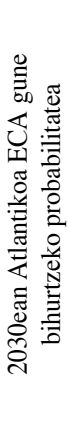 } & $\% 0$ & $\begin{array}{c}\text { Duala } \\
\text { scrubber barik }\end{array}$ & $\begin{array}{c}\text { Duala } \\
\text { scrubber barik }\end{array}$ & $\begin{array}{c}\text { Duala } \\
\text { scrubber barik }\end{array}$ & $\begin{array}{c}\text { Duala } \\
\text { scrubber-arekin }\end{array}$ & $\begin{array}{c}\text { Duala } \\
\text { scrubber-arekin }\end{array}$ \\
\hline & $\% 25$ & $\begin{array}{c}\text { Duala } \\
\text { scrubber barik }\end{array}$ & $\begin{array}{c}\text { Duala } \\
\text { scrubber barik }\end{array}$ & $\begin{array}{c}\text { Duala } \\
\text { scrubber barik }\end{array}$ & $\begin{array}{c}\text { Duala } \\
\text { scrubber-arekin }\end{array}$ & $\begin{array}{c}\text { Duala } \\
\text { scrubber-arekin }\end{array}$ \\
\hline & $\% 50$ & $\begin{array}{c}\text { Duala } \\
\text { scrubber barik }\end{array}$ & $\begin{array}{c}\text { Duala } \\
\text { scrubber barik }\end{array}$ & $\begin{array}{c}\text { Duala } \\
\text { scrubber barik }\end{array}$ & $\begin{array}{c}\text { Duala } \\
\text { scrubber-arekin }\end{array}$ & $\begin{array}{c}\text { Duala } \\
\text { scrubber-arekin }\end{array}$ \\
\hline & $\% 75$ & $\begin{array}{c}\text { Duala } \\
\text { scrubber barik }\end{array}$ & $\begin{array}{c}\text { Duala } \\
\text { scrubber barik }\end{array}$ & $\begin{array}{c}\text { Duala } \\
\text { scrubber-arekin }\end{array}$ & $\begin{array}{c}\text { Duala } \\
\text { scrubber-arekin }\end{array}$ & $\begin{array}{c}\text { Duala } \\
\text { scrubber-arekin }\end{array}$ \\
\hline & $\% 100$ & $\begin{array}{c}\text { Duala } \\
\text { scrubber barik }\end{array}$ & $\begin{array}{c}\text { Duala } \\
\text { scrubber barik }\end{array}$ & $\begin{array}{c}\text { Duala } \\
\text { scrubber-arekin }\end{array}$ & $\begin{array}{c}\text { Duala } \\
\text { scrubber-arekin }\end{array}$ & $\begin{array}{c}\text { Duala } \\
\text { scrubber-arekin }\end{array}$ \\
\hline
\end{tabular}

\section{ONDORIOAK}

Gaur egun, itsasontzien kutsadura murrizteko asmoz, gero eta legedi zorrotzagoak ezartzen ari da nazioarteko komunitatea. Legediaren nondik norakoak eragin handia du armadorearen interes orokorretan, batez ere itsasontzietan erabili beharreko erregaiari dagokionez. Horrenbestez, egoera nagusi bi daude, bata dagoeneko existitzen diren itsasontziena eta bestea itsasontzi berriena. Egoera bakoitzean, edozein delarik ere estrategia, kontuan hartu beharreko aldagai nagusiak honako hauek dira: a) itsasontzien balio-bizitza, b) fuel-olioaren prezioa, c) zer gunetan zehar nabigatuko den, d) zenbat egunetan egongo den ontzia itsasoan, e) aukera teknologikoak eta haien kostua, eta f) legediaren etorkizuneko bilakaera, betiere kontuan izanda gero eta murriztaileagoa izango dela. Gure aurretiko ikerketetan oinarrituz, honako ondorio hauek atera ditugu:

- Dagoeneko nabigatzen ari diren itsasontzien kasuan, bi aukera daude. Batetik, sufre kantitate txikiagoko fuel-olioak kontsumitzea, eta, bestetik, keak iragazteko scrubber delako sistema instalatzea itsasontzian. Aukera hori are egokiagoa da ontziak zenbat eta balio-bizitza handiagoa izan, zenbat eta denbora gehiago nabigatu ECA guneetan zehar eta zenbat eta luzaroagoan egon itsasoan.

- Itsasontzi berri bat egiteko orduan, lau aukera aztertu dira: dieselmotorra edo duala jartzea, eta scrubber-rekin edo scrubber gabe jar- 
Nestor Goicoechea, Harkaitz Eguiraun, Ibon Galarraga, Eneko Solaberrieta, Luis Maria Abadie

tzea. Aukerarik onena, ikusita legedia norantz doan, motor duala eta scrubber-a instalatzea da, nahiz eta jatorrizko inbertsioa handiagoa izan. Aukera horrek, besteak beste, malgutasun handia eskaintzen du erregaia aukeratzeko orduan.

Azkenik, aipatu behar da sortzear den legedi berriak zehaztuko duela, gure ustean, etorkizunean zer pauso eman beharko den. Tamalez, orain arte ez da lortu nazioarte mailan itsas garraioaren legediaren integraziorik, ez ingurumen orokorraren arloan, ez eta klima aldaketaren arloan ere. Beraz etorkizuneko aukerak aldagai askoren arabera egongo direla susmatzen dugu. Gure uste apalean, etorkizun hurbilean nazioarteko komunitateak itsas garraioaren politikak eta legediak bateratu eta integratzeko erronkari aurre egin beharko diola argi dago.

\section{BIBLIOGRAFIA}

[1] ICS. 2014. World Trade and the Reduction of $\mathrm{CO}_{2}$ Emissions, United Nations framework convention on climate change. UNFCC.

[2] UNCTAD. 2016. United Nations Conference on Trade and Development, Review of Maritime Transport. https://unctad.org/en/Pages/Publications/Reviewof-Maritime-Transport-(Series).aspx (sartze data: 2019.eko Urriaren 16a)

[3] LLOYD'S REGISTER GROUP LIMITED. 2019. Global marine trends 2030.

[4] ABADIE, L.M., GOICOECHEA, N. 2019. «Powering newly constructed vessels to comply with ECA regulations under fuel market prices uncertainty: Diesel or dual fuel engine?». Transportation Research Part D, 67, 433-448.

[5] BIALYSTOCKI, N., KONOVESSIS, D. 2016. «On the estimation of ship's fuel consumption and speed curve: A statistical approach». Journal of Ocean Engineering and Science, 1, 157-166.

[6] STOPFORD, M. 2009. Maritime Economics 3rd edition. Routledge, London.

[7] RONEN, D. 2011. «The effect of oil price on containership speed and fleet size». Journal of the Operational Research Society, 62(1), 211-216.

[8] CORBETT, J.J., KÖHLER, H.W. 2003. «Updated emissions from ocean shipping». Journal of Geophysical Research, 108(D20), 4650.

[9] EYRING, V., KÖHLER, H.W., VAN AARDENNE, J., LAUER, A. 2005. «Emissions from International Shipping: The last 50 Years». Journal of Geophysical Research, 110:D17305, 1-12.

[10] ENDRESEN, Ø., SØRGARD, E., SUNDET, J.K., DALSØREN S.B., ISAKSEN I.S.A., BERGLEN, T.F., GRAVIR, G., 2003. «Emission from international sea transportation and environmental impact». Journal of Geophysical Research, 108, D17, 4560, 1-22. 
[11] INTERNATIONAL MARITIME ORGANIZATION IMO. 2009. Second IMO GHG Study 2009, London, UK.

[12] INTERNATIONAL MARITIME ORGANIZATION IMO. 2014. Third IMO GHG Study 2014. London, UK.

[13] REYNOLDS, G.L. 2009. «The reduction of GHG emissions from shipping A key Challenge for the industry». Proceedings of the World Maritime Technology Conference WMRC. 1-4.

[14] WORLD SHIPPING COUNCIL, Carbon emissions. http://www. worldshipping.org/industry-issues/environment/air-emissions/carbonemissions (sartze data: 2019.eko Urriaren 16a).

[15] ABADIE, L.M., GOICOECHEA, N., GALARRAGA, I. 2017. «Adapting the shipping sector to stricter emissions regulations: fuel switching or installing a scrubber?» Transport Research Part D, 57, 237-250.

[16] HASSELlÖV, I., TURNER, D., LAUER, A., CORBETT, J. 2013. «Shipping contributes to ocean acidification». Geophys. Res. Lett. 40, 2731-2736.

[17] FUGLESTVEDT, J., EYRING, V., ISAKSEN, I., LEE, D., SAUSEN, R. «Shipping Emissions: From Cooling to Warming of Climate-and Reducing Impacts on Health Environmental». Science \& Technology, 43-24, 90579062.

[18] SILVA, R.A., ADELMAN, Z., FRY, M.M., WEST, J.J. 2016. «The impact of individual anthropogenic emissions sectors on the global burden of human mortality due to ambient air pollution». Environmental Health Perspective, 124-11. 1776-1784.

[19] SOFIEV, M., WINEBRAKE, J.J., JOHANSSON, L., CARR, E., PRANK, M., SOARES, J., VIRA, J., KOUZNETSOV, R., JALKANEN, J, CORBETT, J.J. 2018. «Cleaner fuels for ships provide public health benefits with climate trade offs». Nature Communications, 9:406, 1-12.

[20] ANDERSSON, K., BRYNOLF, S., 2015. «Marine Fuel Alternatives for a Low Carbon Future - Market Influence on the Pathways selected». International Conference on Shipping in Changing Climates - Technologies, Operations, Logistics and Policies Towards Meeting 2050 Emission Targets. Glasgow, UK.

[21] PANAGAKOS, G.P., STAMATOPOULOU, E.V ., PSARAFTIS, H.N. 2014. «The possible designation of the Mediterranean Sea as a SECA: a case study». Transp. Res. Part D, 28, 74-90.

[22] KONTOVAS, C.A., PANAGAKOS, G., PSARAFTIS, H.N., STAMATOPOULOU, E. 2016. «Being Green on Sulphur: Targets, Measures and SideEffects. Green Transportation Logistics. International Series in Operations Research \& Management Science, vol 226. Springer, Chambers.

[23] WÄRTSILÄ. 2019. www.wärtsilä.com (sartze data: 2019.eko Urriaren 16a).

[24] MARQUARD \& BALHS. 2019. www.marquard-Bahls.com (sartze data: 2019.eko Urriaren 16a).

[25] INTERNATIONAL MARITIME ORGANIZATION IMO. 2015. Nitrogen Oxides (NOx) - Regulation 13. http://www.imo.org/en/OurWork/Environ- 
Nestor Goicoechea, Harkaitz Eguiraun, Ibon Galarraga, Eneko Solaberrieta, Luis Maria Abadie

ment/PollutionPrevention/AirPollution/Pages/Nitrogen-oxides-(NOx)\%E2\%80\%93-Regulation-13.aspx (sartze data: 2019.eko Urriaren 16a).

[26] INTERNATIONAL MARITIME ORGANIZATION IMO. 2015. Sulphur Oxides (SOx) - Regulation 14. http://www.imo.org/en/OurWork/Environment/PollutionPrevention/AirPollution/Pages/Sulphur-oxides-(SOx)\%E2\%80\%93-Regulation-14.aspx (sartze data: 2019.eko Urriaren 16a).

[27] KRISTENSEN, H.O. 2012. Energy demand and exhaust gas emissions of marine engines. Technical University of Denmark. Copenhagen.

[28] PANASIUK, I.; TURKINA, L. 2015. «The evaluation of investments efficiency of SOx scrubber installation». Transportation Research Part D, 40, 87-96. 